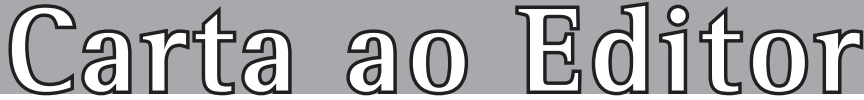

\section{Traqueostomia à beira do leito: considerações práticas}

Bedside tracheostomy: practical considerations

\author{
Ricardo Mingarini Terra', Angelo Fernandez', Ricardo Helbert Bammann²
}

Parabenizamos Perfeito et al.(1) pelo artigo original publicado na última edição de 2007 do Jornal Brasileiro de Pneumologia e compartilhamos a opinião de que a traqueostomia convencional à beira do leito é viável e segura. Nossa experiência com a técnica é semelhante à descrita, com 4,3\% de complicações numa amostra de 552 pacientes estudados. ${ }^{(2)}$ Em nosso trabalho, concluímos que a traqueostomia poderia ser realizada à beira do leito com segurança, mesmo em pacientes obesos, muito idosos, com pós-trauma raquimedular, etc., fatores previamente descritos como contra-indicação à traqueostomia fora de Centro Cirúrgico. (3-5) Também analisamos outras variáveis, como o tempo médio do procedimento (19 $\mathrm{min}$ ) e o custo estimado da operação em nosso meio (253 USD para a técnica aberta e 494 USD para a técnica percutânea na própria UT1; e 496 USD para a técnica aberta no Centro Cirúrgico).

Ressaltamos, no artigo de Perfeito et al., a preocupação com o importante tema do treinamento de residentes, que deve ser o objetivo de um hospital de ensino. Por ser considerado um procedimento cirúrgico simples, a traqueostomia é freqüentemente delegada a cirurgiões menos experientes, sem a devida supervisão. Esta falta de experiência, em um ambiente com menos recursos, pode ter conseqüências indesejáveis, desde o aumento desnecessário do tempo operatório, desgaste da equipe de apoio - não habituada a dificuldades cirúrgicas - até complicações mais desastrosas, principalmente as ligadas à manutenção da ventilação assistida. Sem dúvida, a presença de um cirurgião habituado a manipular o acesso à via aérea é condição importante para a segurança e bons resultados do procedimento.

Todavia, o aspecto principal a ser lembrado neste contexto é que a UTI é um ambiente dinâmico e multidisciplinar. logo, as equipes de intensivistas, enfermeiros e fisioterapeutas devem participar ativamente do processo. Muitas vezes, o desconhecimento leva à resistência quanto à implantação do método e, portanto, a educação continuada é essencial para que todos se sintam seguros e à vontade para a realização da traqueostomia neste ambiente. Um protocolo rígido e de conhecimento de todos os envolvidos deve ser estabelecido e seguido, de acordo com as condições e particularidades de cada instituição. A traqueostomia à beira do leito deve ser uma rotina do serviço, e não uma indicação esporádica para os casos mais graves, com risco de transporte, pois estes pacientes são os que menos suportam períodos de apnéia e estão sob maior risco nos momentos de troca de tubo, especialmente quando o procedimento é feito por uma equipe pouco treinada. Devem estar incluídos neste protocolo: a indicação clínica; o consentimento do paciente ou responsável; o material; os recursos humanos necessários; a técnica cirúrgica; e os cuidados pós-operatórios (fixação correta da cânula, pressões nos balonetes, seguimento tardio até decanulação, etc). Considerando estas premissas, em conjunto com Perfeito et al., a quem congratulamos por levantar um tema tão importante, acreditamos que a traqueostomia convencional pode ser realizada à beira do leito com segurança, constituindo uma opção adequada para pacientes em ventilação mecânica prolongada.

\section{Referências}

1. Perfeito JA, da Mata CA, Forte V, Carnaghi M, Tamura N, Leão LE. Tracheostomy in the ICU: is it worthwhile? J Bras Pneumol 2007;33(6):687-90.

2. Terra RM, Fernandez A, Bammann RH, Castro AC, lshy A, Junqueira JJ. Open bedside tracheostomy: routine procedure for patients under prolonged mechanical ventilation. Clinics 2007;62(4):427-32.

3. Upadhyay A, Maurer J, Turner J, Tiszenkel H, Rosengart T. Elective bedside tracheostomy in the intensive care unit. J Am Coll Surg 1996;183(1):51-5.

4. Wease GL, Frikker M, Villalba M, Glover J. Bedside tracheostomy in the intensive care unit. Arch Surg 1996;131(5):552-4; discussion 554-5.

5. Massick DD, Yao S, Powell DM, Griesen D, Hobgood T, Allen JN, et al. Bedside tracheostomy in the intensive care unit: A prospective randomized trial comparing open surgical tracheostomy with endoscopically guided percutaneous dilational tracheostomy. Laryngoscope 2001;111(3):494-500. 